\title{
Detection of Heavy Metal Ions using Star-Shaped Microfluidic Channel
}

\author{
Chella Santhosh $^{1, *}$, K. Hari Kishore ${ }^{2}$, G. Pavani Lakshmi ${ }^{3}$, G.Kushwanth ${ }^{4}$, P. Rama Krishna Dharma \\ Teja $^{5}$, R. S. Ernest Ravindran ${ }^{6}$, Sree Vardhan Cheerala ${ }^{7}$, M. Ravi Kumar ${ }^{8}$ \\ 1,2,3,4,5,6,7,8 Department of Electronics and Communication Engineering, KLEF, Green Fields, Vaddeswaram, \\ India, *csanthosh@ kluniversity.in
}

\begin{abstract}
These days all most all of the nations are confronting numerous ecological problems of which water contamination is very dangerous and a greater part of these nations are facing tremendous difficulties to overcome this issue. Water contamination because of Heavy Metal Ions is a worldwide issue which requires legitimate attentiveness for keeping up the demand for water quality. A versatile framework made of MEMS sensors equipped for sensing analytes on-site is profoundly required. As needs be, our primary objective is to build up a microfluidic channel that can be utilized for detecting heavy metal ions with the help of a micro cantilever beam. The two sections incorporated in the proposed framework are a star-shaped microfluidic chamber which facilitates the flow of water onto the cantilever beam and a micro cantilever beam for sensing the heavy metal ions.
\end{abstract}

Key words : Heavy metal ions, MEMS, Micro Cantilever beam, Star-shaped Microfluidic channel.

\section{INTRODUCTION}

Water is the most basic and essential need for every living organism. The demand for water supply is increasing but there aren't as many water resources as needed to fulfil the needs of the human beings. Even the available water resources are not meeting the demand for quality. Most of the water resources are contaminated due to various reasons like the wastes from industries, excrement and wastewater from sewers, household activities, some activities of mining, marine dumping, accidental leakage of oil, pesticides, and etc. The mentioned reasons are also responsible for the accumulation of heavy metal ions in the water. The presence of the heavy metal ions in the water will have ill effects on the health of the human beings as well as the organisms that are using the water resources as their shelter were shown in Table-I. Detecting and removing these denser ions isn't an easy task. The conventional method for removing the heavy metal ions from water is very much time consuming and also involves spending a lot money. So, there is an urgent requirement to find an alternate way for sensing and removing the denser ions from water. Many countries around the globe are facing this problem and trying to solve this issue.

The modelling and analysis of DNA enzyme functionalized capacitive type sensor is used for the sensing of $\mathrm{Pb}^{+2}$ ions is introduced in [2] and in [3] SH-SAW sensor was presented. Both of these approaches don't resolve the problem with the cost and portability. The electrodes made up of gold nanoparticles are used for sensing the $\mathrm{Cd}^{+2}$ ions in samples of water but with a limit confined to $2.6 \mathrm{ppb}$ was presented in [4]. $\mathrm{Pb}^{+2}$ was sensed using MEMS chemical sensor inspired by Shark [6] and a screen printed electrodes made up of silver nanoparticles which are stabilized with glutathione [5] were introduced but the devices weren't easily portable. Varieties of micro-cantilever sensors epitomized in fluidic channels and fluidic wells were discussed in [7] and [8] respectively. Some advanced topics were cited as [9-11].

Table 1: Effects of Heavy Metal Ions

\begin{tabular}{|l|l|}
\hline $\begin{array}{c}\text { Heavy Metal } \\
\text { Ions }\end{array}$ & \multicolumn{1}{|c|}{ Effects } \\
\hline Arsenic & $\begin{array}{l}\text { Skin lesions, neurological problems, } \\
\text { internal cancers, pulmonary disease, } \\
\text { hypertension, diabetes mellitus , and } \\
\text { cardiovascular disease. }\end{array}$ \\
\hline Lead & $\begin{array}{l}\text { Mental retardation, allergies, birth defects, } \\
\text { weight loss, brain damage, hyperactivity, } \\
\text { paralysis, muscular weakness, kidney } \\
\text { damage and even leads to death. }\end{array}$ \\
\hline Mercury & $\begin{array}{l}\text { Damages the brain, alter brain functions, } \\
\text { damage to kidneys and the developing } \\
\text { fetus, irritability, changes in vision or } \\
\text { hearing, tremors, and memory problems. }\end{array}$ \\
\hline Cadmium & $\begin{array}{l}\text { Highly toxic to the kidney, damage to the } \\
\text { skeletal system, irregularities in calcium } \\
\text { metabolism, extreme damage of the lungs, } \\
\text { stomach irritation and result in vomiting. }\end{array}$ \\
\hline Chromium & $\begin{array}{l}\text { Irritates the skin and cause ulceration. } \\
\text { Long-term exposure can cause kidney and } \\
\text { liver damage, and damage to nerve tissue } \\
\text { and circulatory system. }\end{array}$ \\
\hline
\end{tabular}


In this paper we are mainly concentrating on detecting the cadmium ions present in a sample of water with the help of a star-shaped microfluidic channel and a micro-cantilever beam. The effects of cadmium are more adverse as compared to that of other metal ions. Cadmium enters our body via ingestion or inhalation. When we drink the water or swallow the food that contains cadmium the metal ions are amassed in our bodies. So we are sensing the presence of cadmium ions in the water sample.

\section{METHODOLOGY}

In this paper, we have designed a sensor which can be segregated into two sections of which one is the microfluidic channel which is sin the shape of a star and the other is the micro-cantilever beam. For designing the channel we have opted the 'laminar flow' physics and for designing the micro-cantilever beam we have opted the 'solid mechanics' physics.

\section{A. Laminar Flow}

Laminar flow is a field of fluid mechanics in which the fluid that is either gas or liquid travels smoothly following regular patterns unlike the turbulent flow in which liquid flows in irregular patterns. Laminar flow is also called streamline flow. Generally, we use laminar flow when the length of the channel where the fluid flows is moderately small, or when fluid is travelling with low velocity, and when there is high viscosity.

\section{laminar flow}

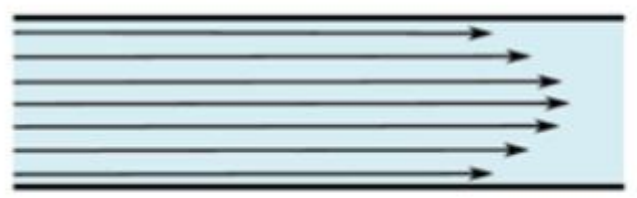

Figure 1: Laminar Flow Of a Fluid

\section{B. Solid Mechanics}

Solid mechanics, a branch of continuum mechanics, is a study of the nature of the materials in solid form. The study includes the motion of the material, deflections or the deformations in the material when subjected to external force, pressure or some changes in temperature and phase.

In our paper, we are going to study the deflections in the micro-cantilever beam (solid) caused due to the force exerted by the denser ions which are held on the surface of the $\mathrm{Au}$ protein layer.

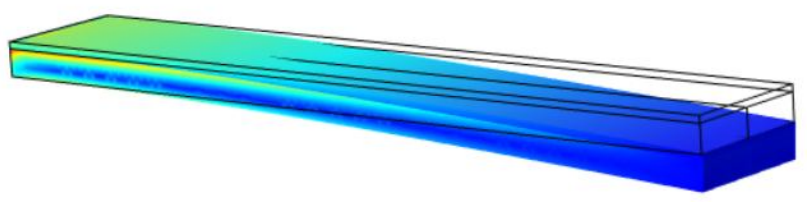

Figure 2: Deflections in cantilever beam (solid)
In COMSOL Multiphysics the structural mechanics is an extra element which helps in modelling the sensor, actuators, and etc. The interfaces provided by the solid mechanics which are available in 3D, 2D pivotal symmetry give the broadest way to deal with dissecting strong structures. Investigating circumstances with subjectively huge turns and strains is III.

\section{DESIGN}

We have utilized COMSOL Multiphysics for designing our framework. We have other different platforms like Ansys for designing the framework however we can't stimulate and investigate the obtained outcomes. So as to perform stimulations on the structured model we utilize the COMSOL Multiphysics.

The designed star-shaped channel has 5 inlets or bays and 1 outlet for the water to flow through the channel.

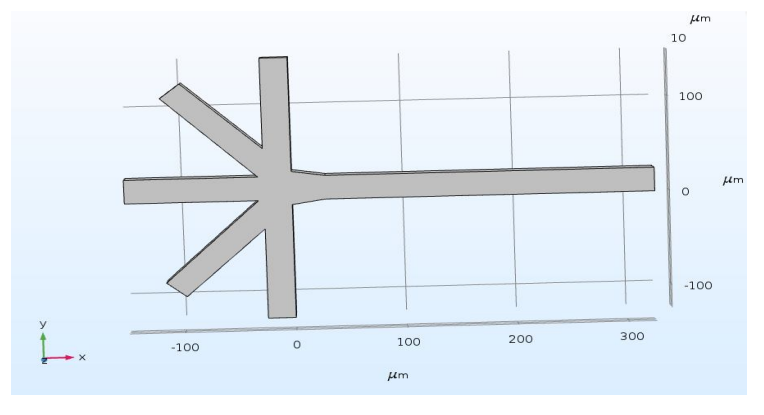

Figure 3: Model geometry of star-shaped channel

At the end of the outlet we model a cantilever beam so that the water flows onto the beam via the channel. Cantilever beam is fabricated using silicon material. Gold protein layer is coated on top of the beam so as to bind the cadmium ions.

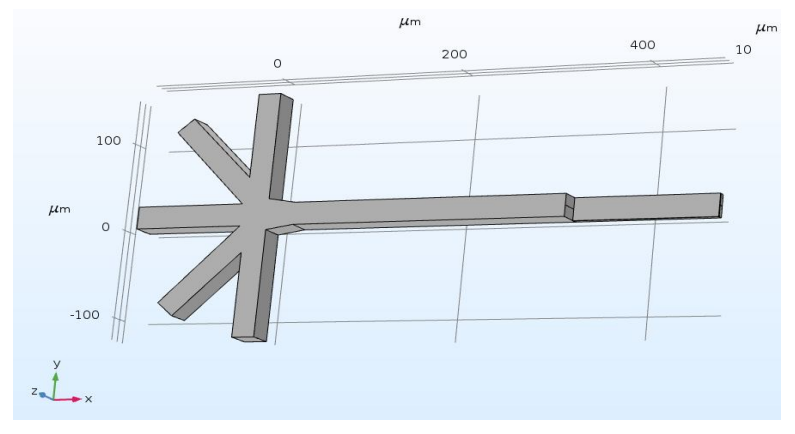

Figure 4: Cantilever beam modelled at the end of the channel outlet

\section{SIMULATION AND RESULTS}

\section{A. Plots of Star-Shaped Microchannel}

Figure 5 and figure 6 shows the velocity field and pressure through the centre of the geometry at $t=1 \mathrm{~s}$. Setting up and watching this plot gives an instructive and subjective depiction of the procedure [1]. 


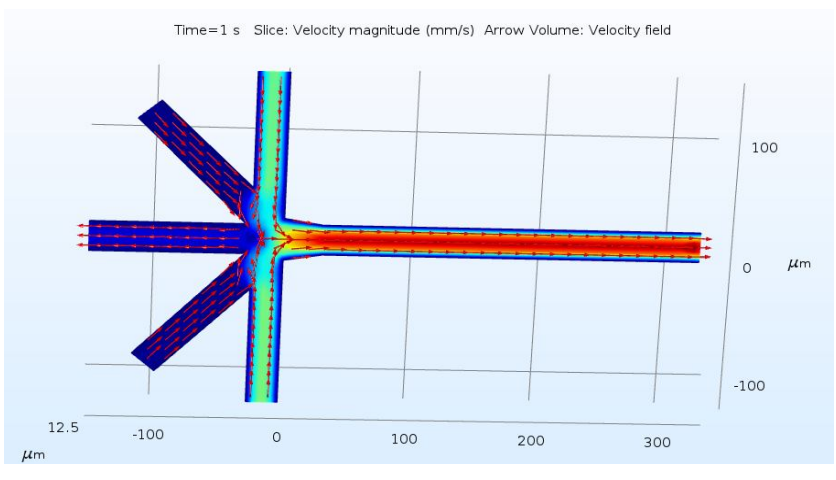

Figure 5: Velocity field in microchannel

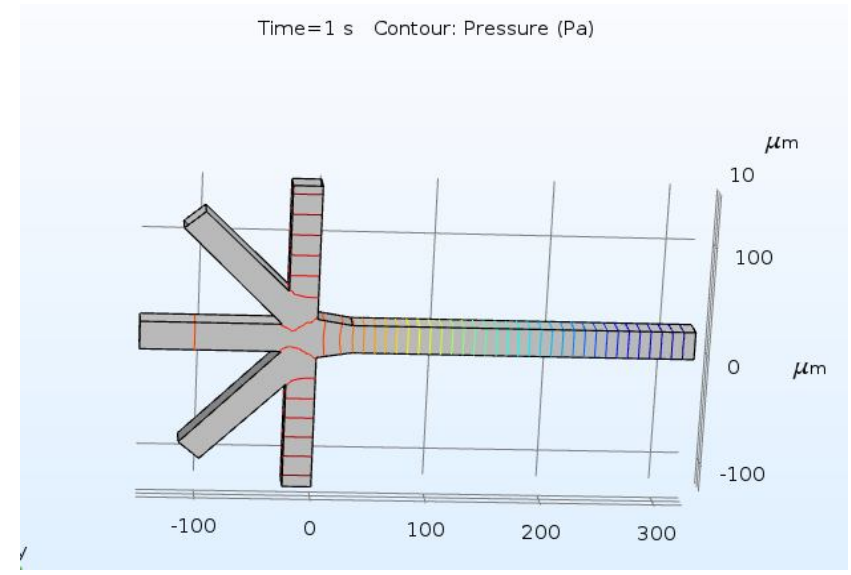

Figure 6: Pressure field in microchannel

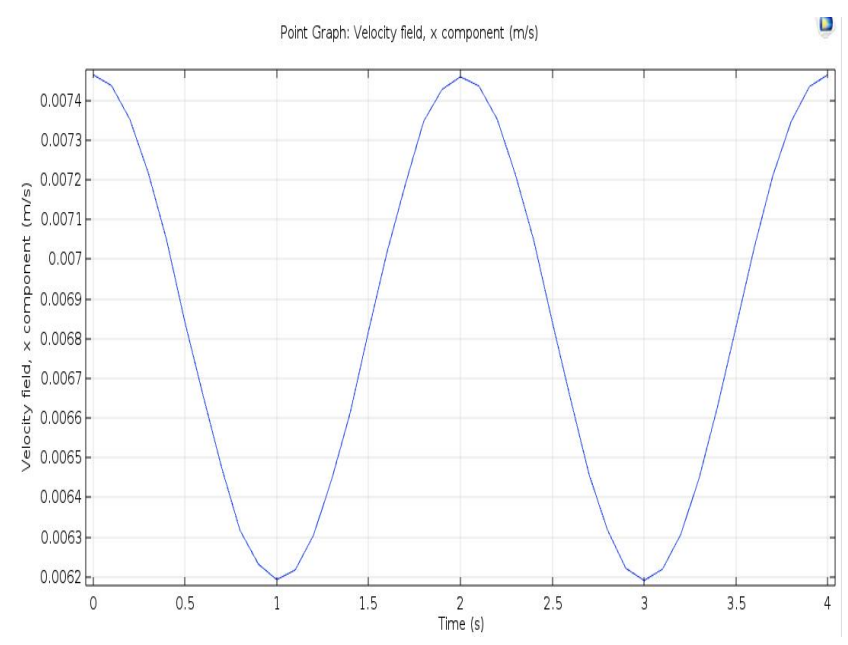

Figure 7: Velocity in the direction of $\mathrm{x}$-axis in microchannel

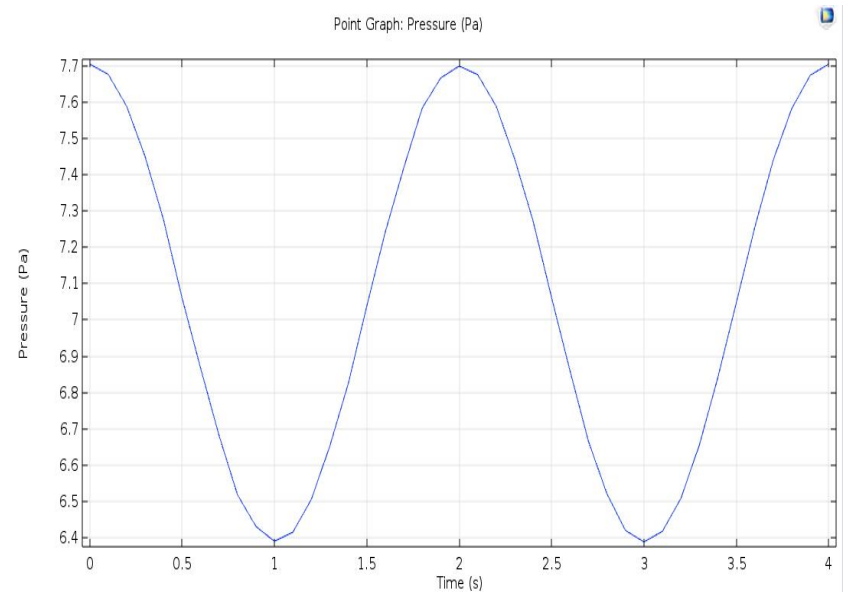

Figure 8: Pressure $(\mathrm{Pa})$ at a point close to the outlet

B.Plots of Star-Shaped Microchannel with Cantilever Beam In Fig.9, when a force of $8.4827 \mathrm{e}^{-14}$ is applied on the beam then the deflection is $1.293 \mathrm{e}^{-19}$. This is the point where we consider that just one cadmium ion is available in 1 cubic $\mu \mathrm{m}$.

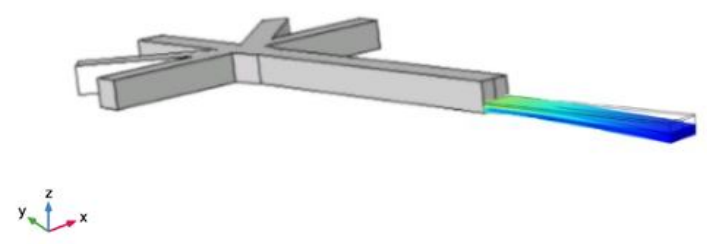

Figure 9: Deflection of beam at force $=8.4827 \mathrm{e}^{-14} \mathrm{~N}$

In Fig.10, when a force of $8.4827 \mathrm{e}^{-13}$ is applied on the beam then the deflection is $1.293 \mathrm{e}^{-18}$. This is the point where we consider that ten cadmium ions are available $t$ in 1 cubic $\mu \mathrm{m}$.

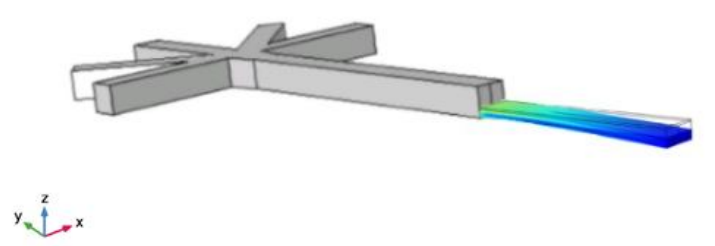

Figure 10: Deflection of beam at force $=8.4827 \mathrm{e}^{-13} \mathrm{~N}$

In Fig.11, when a force of $1.6965 \mathrm{e}^{-12}$ is applied on the beam then the deflection is $2.5859 \mathrm{e}^{-18}$. This is the point where we consider that twenty cadmium ions are available in 1 cubic $\mu \mathrm{m}$. 


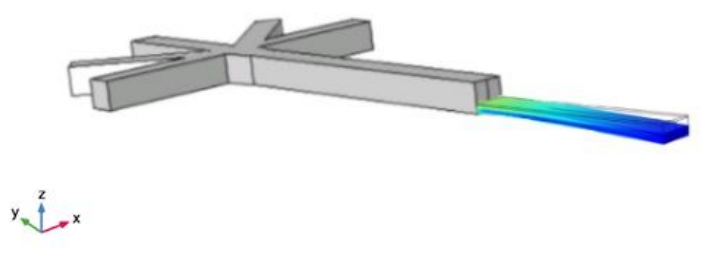

Figure 11: Deflection of beam at force $=1.6965 \mathrm{e}^{-12} \mathrm{~N}$

In Fig.12, when a force of $4.24137 \mathrm{e}^{-12}$ is applied on the beam then the deflection is $6.4650 \mathrm{e}^{-18}$. This is the point where we consider that fifty cadmium ions are available in 1 cubic $\mu \mathrm{m}$. The overall force vs displacement was shown in Table-II.

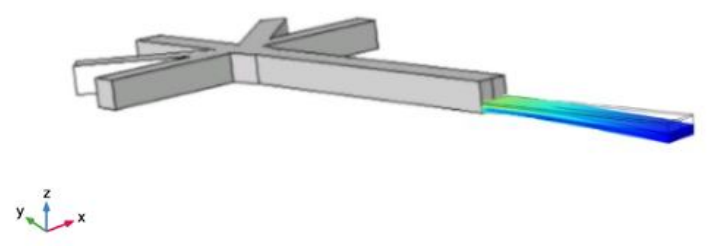

Figure 12: Deflection of beam at force $=4.24137 \mathrm{e}^{-12} \mathrm{~N}$.

Table 2: Force Vs Displacement

\begin{tabular}{|c|c|c|}
\hline $\operatorname{Mass}(\mu \mathrm{g})$ & Force $(\mathrm{N})$ & Displacement $(\mu \mathrm{m})$ \\
\hline $8.65 \mathrm{e}^{-6}$ & $8.4827 \mathrm{e}^{-14}$ & $1.2930 \mathrm{e}^{-19}$ \\
\hline $8.65 \mathrm{e}^{-5}$ & $8.4827 \mathrm{e}^{-13}$ & $1.2930 \mathrm{e}^{-18}$ \\
\hline $1.73 \mathrm{e}^{-4}$ & $1.6965 \mathrm{e}^{-12}$ & $2.5859 \mathrm{e}^{-18}$ \\
\hline $4.325 \mathrm{e}^{-4}$ & $4.24137 \mathrm{e}^{-12}$ & $6.4650 \mathrm{e}^{-18}$ \\
\hline
\end{tabular}

\section{CONCLUSION}

Consequently the deflections along the beam increments as the force increases that is the force exerted on the beam is directly proportional to the amount of deflections along the beam. As the quantity of cadmium ions in the samples increases, the force exerted by the ions on the beam also increases.

Accordingly, from the deflections of the beam we can conclude that cadmium ions are available in the sample that is used for testing. The structured system can be further improvised for efficient sensing and exclusion of heavy metals from water. Utilizing this framework we can even model a structure which can sense multiple heavy metals apart from cadmium. This is conceivable by utilizing distinct protein layers as coating on the cantilever beam.

\section{REFERENCES}

[1] D. Rotakea and A. D. Darji, Heavy metal ion detection in water using MEMS based sensor, Materials Today: Proceedings, Vol. 5, 2018. https://doi.org/10.1016/j.matpr.2017.11.242

[2] G. Tsekenis, M.K. Filippidou, M. Chatzipetrou, V. Tsouti,I. Zergioti and S. Chatzandroulis, Heavy metal ion detection using a capacitive micromechanical biosensor array for environmental monitoring, Sensors and Actuators (Chemical), 2015.

[3] Z. R. Binu, B. N. Avuthu, S. G. Reddy, Massood Z. Atashbar , Jared T. Wabeke and Sherine O. Obare, SH-SAW- Based Sensor for Heavy Metal Ion Detection, IEEE, 2015.

[4] L. Zhang, D.W. Li, W. Song, L. Shi, Y. Li, and Y.T. Long, High Sensitive On-Site Cadmium Sensor Based on AuNPs Amalgam Modified Screen-Printed Carbon Electrodes, IEEE sensors journal, 2010.

[5] I.V. Anambiga, V. Suganthan, N. Arunai Nambi Raj and A. Siva Kumar, Electrochemical Sensor for the Detection of Lead Ions, IEEE ICANMEET, 2013.

[6] N. Wang, E. Kanhere, M.S. Triantafyllou and J.M. Miao, Shark-inspired mems chemical sensor with epithelium-like micropillar electrode array for lead detection, IEEE Transducers, 2015.

[7] W. Xiang and C. Lee, Nanophotonics Sensor Based on Microcantilever for Chemical Analysis, IEEE journal of selected topics in quantum electronics, 2009.

[8] W.J. Venstra, W.H. Wien, P.M. Sarro and J. van Eijk, Microcantilevers encapsulated in fluid wells for sensing in liquids, Microelectronics Engineering Vol. 97, 2012.

[9] S. Kevin Andrews, V.Jeyabalaraja, M.S.Josephine, Vehicle Information System using R-Pi and Internet of Things, International Journal of Advanced Trends in Computer Science and Engineering, Volume 8, No.5, September - October 2019.

https://doi.org/10.30534/ijatcse/2019/46852019

[10] S.S. Khabarov, A.V. Faustov, A.L. Buzhilov, N.L. Lvov, Algorithm for assessing the technical condition of Aircraft structures using a Control System on Fiber Optic Sensors, International Journal of Advanced Trends in Computer Science and Engineering, Volume 8, No.5, September - October 2019.

https://doi.org/10.30534/ijatcse/2019/37852019

[11] O. Amer, A. Salem, A Novel Leach Routing Protocol using Genetic Algorithm for Wireless Sensor Networks, International Journal of Advanced Trends in Computer Science and Engineering, Volume 8, No.5, September October 2019 